\title{
Mass size distributions and size resolved chemical composition of fine particulate matter at the Pittsburgh supersite
}

\author{
Juan C. Cabada ${ }^{\mathrm{a}}$, Sarah Rees ${ }^{\mathrm{b}, \mathrm{d}}$, Satoshi Takahama ${ }^{\mathrm{a}}$, Andrey Khlystov ${ }^{\mathrm{a}}$, \\ Spyros N. Pandis ${ }^{\mathrm{a}, \mathrm{d}, *}$, Cliff I. Davidson ${ }^{\mathrm{b}, \mathrm{d}}$, Allen L. Robinson ${ }^{\mathrm{c}, \mathrm{d}}$ \\ a Department of Chemical Engineering, Carnegie Mellon University, Pittsburgh, PA 15213-7139, USA \\ ${ }^{\mathrm{b}}$ Department of Civil and Environmental Engineering, Carnegie Mellon University, Pittsburgh, PA 15213-7139, USA \\ ${ }^{\mathrm{c}}$ Department of Mechanical Engineering, Carnegie Mellon University, PA 15213-7139, USA \\ ${ }^{\mathrm{d}}$ Department of Engineering and Public Policy, Carnegie Mellon University, Pittsburgh, PA 15213-7139, USA
}

\begin{abstract}
Size-resolved aerosol mass and chemical composition were measured during the Pittsburgh Air Quality Study. Daily samples were collected for 12 months from July 2001 to June 2002. Micro-orifice uniform deposit impactors (MOUDIs) were used to collect aerosol samples of fine particulate matter smaller than $10 \mu \mathrm{m}$. Measurements of $\mathrm{PM}_{0.056}, \mathrm{PM}_{0.10}$, $\mathrm{PM}_{0.18}, \mathrm{PM}_{0.32}, \mathrm{PM}_{0.56}, \mathrm{PM}_{1.0}, \mathrm{PM}_{1.8}$ and $\mathrm{PM}_{2.5}$ with the MOUDI are available for the full study period. Seasonal variations in the concentrations are observed for all size cuts. Higher concentrations are observed during the summer and lower during the winter.

Comparison between the $\mathrm{PM}_{2.5}$ measurements by the MOUDI and other integrated PM samplers reveals good agreement. Good correlation is observed for $\mathrm{PM}_{10}$ between the MOUDI and an integrated sampler but the MOUDI underestimates $\mathrm{PM}_{10}$ by $20 \%$. Bouncing of particles from higher stages of the MOUDI $\left(>\mathrm{PM}_{2.5}\right)$ is not a major problem because of the low concentrations of coarse particles in the area. The main cause of coarse particle losses appears to be losses to the wall of the MOUDI.

Samples were collected on aluminum foils for analysis of carbonaceous material and on Teflon filters for analysis of particle mass and inorganic anions and cations. Daily samples were analyzed during the summer (July 2001) and the winter intensives (January 2002). During the summer around 50\% of the organic material is lost from the aluminum foils as compared to a filter-based sampler. These losses are due to volatilization and bounce-off from the MOUDI stages. High nitrate losses from the MOUDI are also observed during the summer (above $70 \%$ ). Good agreement between the gravimetrically determined mass and the sum of the masses of the individual compounds is obtained, if the lost mass from organics and the aerosol water content are included for the summer. For the winter no significant losses of material are detected and there exists reasonable agreement between the gravimetrical mass and the sum of the concentrations of the individual compounds.

Ultrafine particles (below $100 \mathrm{~nm}$ ) account on average, for $<5 \%$ of the $\mathrm{PM}_{2.5}$ mass, and show different composition for the summer and the winter. During the summer the ultrafine mass is $50 \%$ carbonaceous material (organic material and elemental carbon) and 50\% inorganic (mainly sulfate and ammonium); during the winter these percentages are $70 \%$ and $30 \%$, respectively.
\end{abstract}

(C) 2004 Elsevier Ltd. All rights reserved.

Keywords: MOUDI; $\mathrm{PM}_{x}$; PM size/composition; Condensation mode; Droplet mode; Ultrafine PM; PAQS

\footnotetext{
*Corresponding author. Department of Chemical Engineering, Carnegie Mellon University, Pittsburgh, PA 15213-7139, USA.

E-mail address: spyros@andrew.cmu.edu (S.N. Pandis).
} 


\section{Introduction}

Fine atmospheric aerosol mass concentrations (particulate matter below $2.5 \mu \mathrm{m}, \mathrm{PM}_{2.5}$ ) are of importance because of their impact on human health (Dockery et al., 1993), their ability to scatter light affecting visibility, and their role in global climate change (Seinfeld and Pandis, 1998). Fine particulate matter size distributions can provide information about the chemical and physical processes affecting aerosols as they are transported in the atmosphere (Wall et al., 1988). Aerosol size distributions also are important for the optical properties and the effect of aerosols on the planet energy balance (Seinfeld and Pandis, 1998).

Particles emitted from combustion sources (primary emissions) and produced by nucleation start their atmospheric lifetime in the smaller particle sizes (diameters $<200 \mathrm{~nm}$ ). Condensation of organic compounds after the reaction of atmospheric oxidants and organic gases (secondary organic aerosol, SOA) and secondary production of sulfate affects mainly the accumulation mode between 200 and $500 \mathrm{~nm}$. Longrange transported and cloud-processed aerosol tend to be in the 200-1000 nm diameter range (Whitby, 1978; Wexler and Ondov, 1998; Seinfeld and Pandis, 1998).

Recently, attention has been drawn to the ultrafine (diameter below $100 \mathrm{~nm}$ ) aerosol concentrations. Ultrafine particles account for practically all the aerosol number concentration in the urban atmosphere, though their mass contribution is in general small. These particles can penetrate deep into the interstitial space of the lungs and overwhelm the alveolar macrophages, thereby impeding the natural cleaning mechanisms of the lungs (Oberdorster et al., 1994; Oberdorster, 1995, 2001; Ferin et al., 1992). Furthermore, inhalation of highly acidic particles can cause inflammation and irritation of the lung tissue; if the chemical constituents of the particles are carcinogenic, these particles may induce cancer tumors (Oberdorster and $\mathrm{Yu}, 1990$; Donalson et al., 2002). Fine-particle regulations in the US are focused on controlling the PM mass concentration $\left(\mathrm{PM}_{10}\right.$ and $\left.\mathrm{PM}_{2.5}\right)$ (Environmental Protection Agency, 1996). The effect of reductions of the $\mathrm{PM}_{2.5}$ and $\mathrm{PM}_{10}$ on the concentration of ultrafine particles is not well understood. Ultrafine particles are emitted mainly from mobile sources (automobiles and diesel trucks) and stationary combustion sources. However, they are also formed during the nucleation of sulfuric acid and organic gases (Seinfeld and Pandis, 1998).

Results of studies combining measurements of aerosol number concentrations and chemically speciated size distributions, using micro-orifice uniform deposit impactors (MOUDIs), are limited to southern and central California (Hughes et al., 1998; Chung et al., 2001). Both of these studies were done during the winter. For Southern California (Pasadena) carbonaceous material was the largest fraction of the $\mathrm{PM}_{2.5}$, followed by nitrate. Small contributions of sulfate, ammonium and trace compounds were reported for this winter aerosol. An "unknown" component was determined by the difference between the gravimetrically measured mass and the sum of the masses of the individual compounds on each MOUDI stage. Larger values of "unknown" material are associated with the upper stages of the MOUDI (between 0.32 and $1.0 \mu \mathrm{m}$ ). The fraction of this "unknown" material is reported to be of the order of 10-30\%. Central California (Bakersfield) was characterized by periods of clean and polluted air during the winter. Clean days were characterized by high fractions of carbonaceous material, nitrate and ammonium in the $\mathrm{PM}_{2.5}$. During polluted days particles contained mainly sulfate, nitrate, sodium and chloride. On the clean days, the reported "unknown" mass was negligible, although this discrepancy was significantly larger on polluted days, occasionally over $30 \%$.

The studies of Hughes et al. (1998) and Chung et al. (2001) also provided information on ultrafines particles. Both of these studies reported a lack of correlation between ultrafine number and ultrafine mass concentrations. Carbonaceous compounds were the largest fraction of the ultrafine mass. Significant contributions of sulfate, nitrate and trace compounds were reported in both studies. The unknown fraction of material in the ultrafine particles was reported to be between $0 \%$ and $50 \%$.

In this paper we present data on particle mass concentrations in several size ranges $(0.056-10 \mu \mathrm{m})$ collected in the Pittsburgh Air Quality Study (PAQS) from July 2001 to June 2002. For two intensive periods, during 15 days in the summer of 2001 and 9 days in the winter of 2002, impactor samples were chemically resolved for inorganic components and carbonaceous compounds.

\section{Experimental}

MOUDIs (Marple et al., 1991) (Model 110, MSP Co., Minneapolis, MN) were used to collect daily sizeresolved aerosol samples during PAQS, from July 2001 to June 2002. Aerodynamic size cuts for the impactor are $0.056,0.10,0.18,0.32,0.56,1.0,1.8,2.5,5.6$ and $10 \mu \mathrm{m}$. The MOUDI sampling flow rate is $301 \mathrm{~min}^{-1}$. The PAQS main site was located in Schenley park on the top of a hill adjacent to the Carnegie Mellon University campus, around $6 \mathrm{~km}$ east of downtown Pittsburgh.

Samples for the determination of total mass were collected using $37 \mathrm{~mm}$ ring-supported Teflon filters (7592-104, Whatman, Clifton, NJ). The mass size distribution of the aerosol collected by the MOUDI stages was determined by weighing the filters using a high-precision microbalance (UMX2, Mettler-Toledo, 
Columbus, $\mathrm{OH}$ ). The MOUDI filters were weighed inside a glove box with a controlled relative humidity $(35 \pm 2 \%)$ and temperature $\left(21 \pm 1^{\circ} \mathrm{C}\right)$. Prior to weighing, the filters were equilibrated for $24 \mathrm{~h}$ inside the glove box. During two intensive sampling periods, July of 2001 and January of 2002, two MOUDI samplers were operated in parallel using different filter media to collect aerosol particles. Teflon filters were used for determination of total mass and inorganic compounds, and uncoated aluminum foils (MSP Corp.) were used for the determination of carbonaceous aerosol concentrations. Inorganic compound concentrations were determined by ion chromatography (Dionex DX-600 for anions and DX-120 for cations) and carbonaceous aerosol was analyzed using a thermal/optical transmittance carbon analyzer (Sunset Laboratory Inc., OC-EC Aerosol Carbon Analyzer Model-3) and temperature program based on the NIOSH protocol (Cabada et al., 2003). In the case of aluminum foils it is not possible to determine the organic carbon (OC), elemental carbon (EC) split by the optical transmittance method. Since aluminum foil loads are low, the possible pyrolisis of material is reduced. For this case, the OC concentrations were determined by the amount of carbon evolved during the helium atmosphere in the analysis and the EC was considered to be the carbon evolved during the helium/oxygen atmosphere. Viidanoja et al. (2002) reported that defining organic and elemental carbon without an optical correction for pyrolisis leads to an upper limit in the estimation of EC and an error within $30 \%$ of the real EC concentration. This change in definition has a small effect on the OC concentration $(<10 \%)$.

Aluminum foils were baked at $550^{\circ} \mathrm{C}$ for $24 \mathrm{~h}$ prior to collection. The MOUDI collecting carbonaceous material was operated without rotating the impactor stages, as a multi-orifice impactor (MOI). OC concentrations measured by the carbon analyzer are converted to organic mass $(\mathrm{OM})$ multiplying by a factor of 1.8 to account for the hydrogen, oxygen, sulfur and nitrogen associated with the organic compounds (Turpin and Lim, 2001).

Measurements of $\mathrm{PM}_{0.056}, \mathrm{PM}_{0.01}, \mathrm{PM}_{0.18}, \mathrm{PM}_{0.32}$, $\mathrm{PM}_{0.56}, \mathrm{PM}_{1.0}, \mathrm{PM}_{1.8}$ and $\mathrm{PM}_{2.5}$ with the MOUDI are available for the full study period, while $\mathrm{PM}_{5.6}$ and $\mathrm{PM}_{10}$ measurements were conducted only during 2001 . Independent measurements of $\mathrm{PM}_{10}$ with a dichotomous sampler are available for the full study.

Particle bounce-off in cascade impactors has been documented by several authors, particles as small as $0.2 \mu \mathrm{m}$ can bounce from their respective collection stage and are collected on stages corresponding to smaller sizes (Hinds, 1998; Pak et al., 1992). This problem is more common in the upper stages of the impactors. Experimental data show that once a large particle bounces-off its proper stage it is likely to continue bouncing-off other stages in the impactor and may not be collected at all (Hinds, 1998). The use of fine PM cyclones in front of cascade impactors and the use of greased substrates can reduce this problem (Hinds, 1998). For this study greased Teflon substrates were used for MOUDI stages collecting particles larger than $10 \mu \mathrm{m}$. No greased stages were used for the MOUDI with aluminum foils substrates to avoid contamination of organic material.

A dry-ambient aerosol size spectrometer (DAASS) system (Stanier et al., 2003) operated during PAQS reporting number, surface area and volume distributions of aerosols. The system consists of two scanning mobility particle sizers (SMPS, TSI 3936N25 and TSI 3936L10) and an aerodynamic particle sizer (APS, TSI APS 3320) that measure the aerosol size distribution between $3 \mathrm{~nm}$ and $10 \mu \mathrm{m}$ in diameter. The inlets of the instruments and their sheath air lines were equipped with computer-controlled valves that direct air through Nafion dryers or bypass them. The Nafion dryers reduce the $\mathrm{RH}$ to below $30 \%$, at which ambient particles are expected to lose most or all of the water and thus be virtually dry. The instrument cycles between dried and the ambient conditions every $7 \mathrm{~min}$ and is synchronized with the scan times of the aerosol spectrometers.

In addition to the size-resolved measurements using the MOUDI and the DAASS system, integrated $\mathrm{PM}_{10}$ and $\mathrm{PM}_{2.5}$ samplers were operated at PAQS from July 2001 to July 2002. A dichotomous sampler (Series 241, Thermo Andersen) measured daily average $\mathrm{PM}_{10}$ and $\mathrm{PM}_{2.5}$ mass on Teflon filters (7592-104, Whatman), with operational flow of $16.71 \mathrm{~min}^{-1}$. An FRM sampler (Partisol-2000, Rupprecht \& Patashnick Co., Inc.) measured daily average $\mathrm{PM}_{2.5}$ mass on Teflon substrates (7592-104, Whatman), operating at $16.71 \mathrm{~min}^{-1}$. Determination of mass from these filters followed the same procedure as for the MOUDI Teflon filters. A tapered element oscillating microbalance (TEOM, Series 1400a, Rupprecht \& Patashnick Co., Inc.) operated continuously for the length of the PAQS project, reporting $\mathrm{PM}_{2.5}$ mass. The TEOM sampled at $30^{\circ} \mathrm{C}$ and was equipped with a Nafion diffusion dryer sample equilibration system (SES, Rupprecht \& Patashnick Co., Inc.).

Several $\mathrm{PM}_{2.5}$ speciation samplers were used during PAQS. Filter-based organic material measurements were collected on quartz fiber filters $(47 \mathrm{~mm}$ Pallflex, QAOT) on a daily basis using a denuded sampler during the summer. During the winter, an undenuded sampler using a front quartz filter and a backup quartz filter was used (Cabada et al., 2004). For the winter, the concentrations measured by the undenuded sampler were corrected for positive artifact by subtracting the measured organic concentration in the backup filter (Subramanian et al., 2004). Measurements of total concentrations of nitrate and ammonium $\left(\mathrm{PM}_{2.5}\right.$ and 
gas), aerosol sulfate, sodium, potassium, magnesium, calcium, chloride, nitrite and oxalate were made using Teflon (Whatman Cat No. 7592-104) and nylon filters (Whatman Cat No. 7410-004). Daily samples were collected during the length of the project except for the summer 2001 intensive period (July 2001), where five samples a day were collected (4-6h samples). Two sampling lines were used for these species, one denuded and one undenuded, to provide data for both gas and particulate phase compounds. Analysis of the inorganic material was performed by ion chromatography (Wittig et al., 2003a).

\section{3. $\mathbf{P M}_{10}$ and $\mathbf{P M}_{2.5}$ measurements}

Fig. 1 shows the intercomparison of $\mathrm{PM}_{2.5}$ and $\mathrm{PM}_{10}$ mass concentrations measured by the MOUDI with corresponding measurements by the dichotomous sampler, FRM and TEOM. The correlation coefficient $\left(R^{2}\right)$ exceeded 0.75 , for the comparisons between the different samplers. However, the original data indicate coarse particle losses from the MOUDI. On average, the MOUDI collects $15-20 \%$ less $\mathrm{PM}_{10}$ mass than the dichotomous sampler. The integrated fine mass collected by the MOUDI (sum of all stages up to $2.5 \mu \mathrm{m}$ ) and the filter-based gravimetrical methods (FRM and dichotomous) are in good agreement. These results are consistent with losses to the walls of some mainly coarse particles in the MOUDI and limited bounce-off from the larger to the smaller stages. Particles during PAQS are expected to be liquid during most of the study because of their ability to retain water at low $\mathrm{RH}$ during the summer (Stanier et al., 2003) and their high organic content during the winter (Wittig et al., 2003b). The comparison between the MOUDI and the TEOM for $\mathrm{PM}_{2.5}$ shows that the MOUDI measures, on average, around $5 \%$ less mass than the TEOM. Statistical analyses show no significant difference between these two measurements.

\section{4. $\mathbf{P M}_{x}$ mass concentrations}

The MOUDI results were used to construct time series of the different PM concentrations measured. Fig. 2 shows the monthly averaged concentrations for the different size cuts, from $\mathrm{PM}_{10}$ to $\mathrm{PM}_{0.056}$. A seasonal dependence is observed for all PM sizes, with higher concentrations observed during the summer and lower during the winter. Lower size cuts mass concentrations show more variability.

Comparisons between mass concentrations measured in the different stages of the MOUDI show that good correlations exist between $\mathrm{PM}_{2.5}$ and $\mathrm{PM}_{x}$, when $\mathrm{PM}_{x}$ is close to $\mathrm{PM}_{2.5}$. The correlation between the different concentrations decreases significantly as $\mathrm{PM}_{x}$ is smaller than $\mathrm{PM}_{0.56}$. On average, around $80 \%$ of the $\mathrm{PM}_{10}$ is
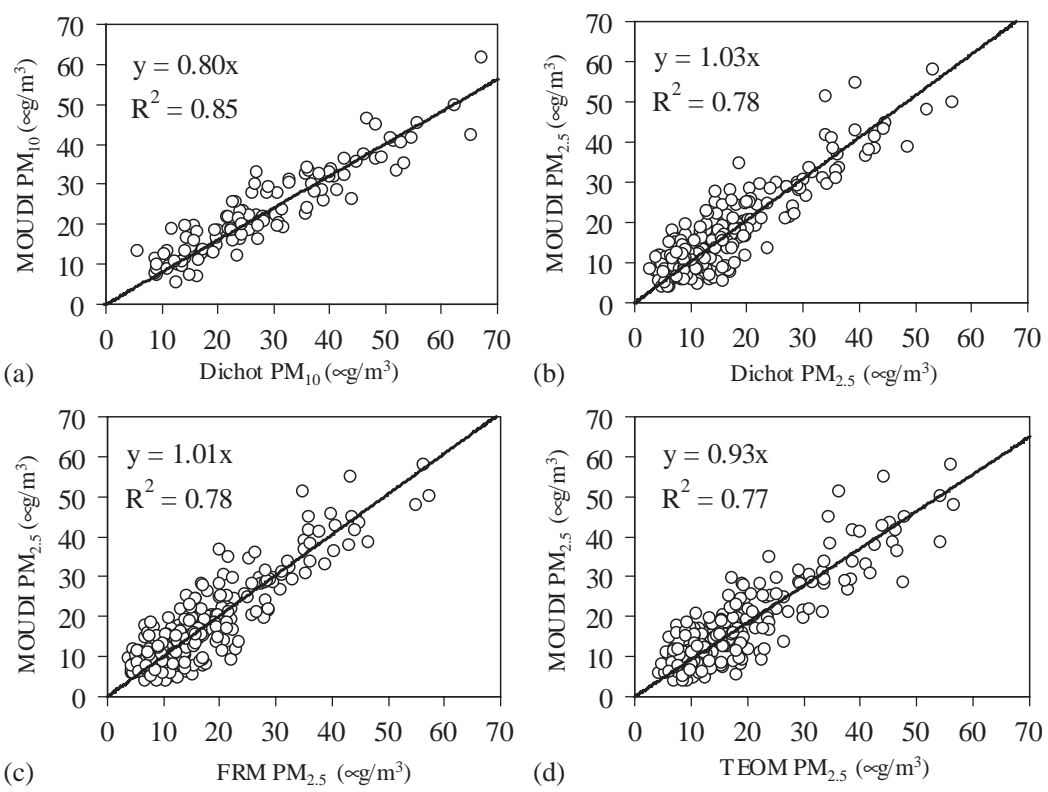

Fig. 1. Sampler inter-comparisons at PAQS, with forced fits through the origin. (a) MOUDI PM 10 vs. Dichot PM 10 for 2001. (b) MOUDI $\mathrm{PM}_{2.5}$ vs. Dichot $\mathrm{PM}_{2.5}$ for 2001 and 2002. (c) MOUDI $\mathrm{PM}_{2.5}$ vs. FRM $\mathrm{PM}_{2.5}$ for 2001 and 2002. (d) MOUDI PM 2.5 vs. TEOM $\mathrm{PM}_{2.5}$ for 2001 and 2002. All measurements are daily averages. 


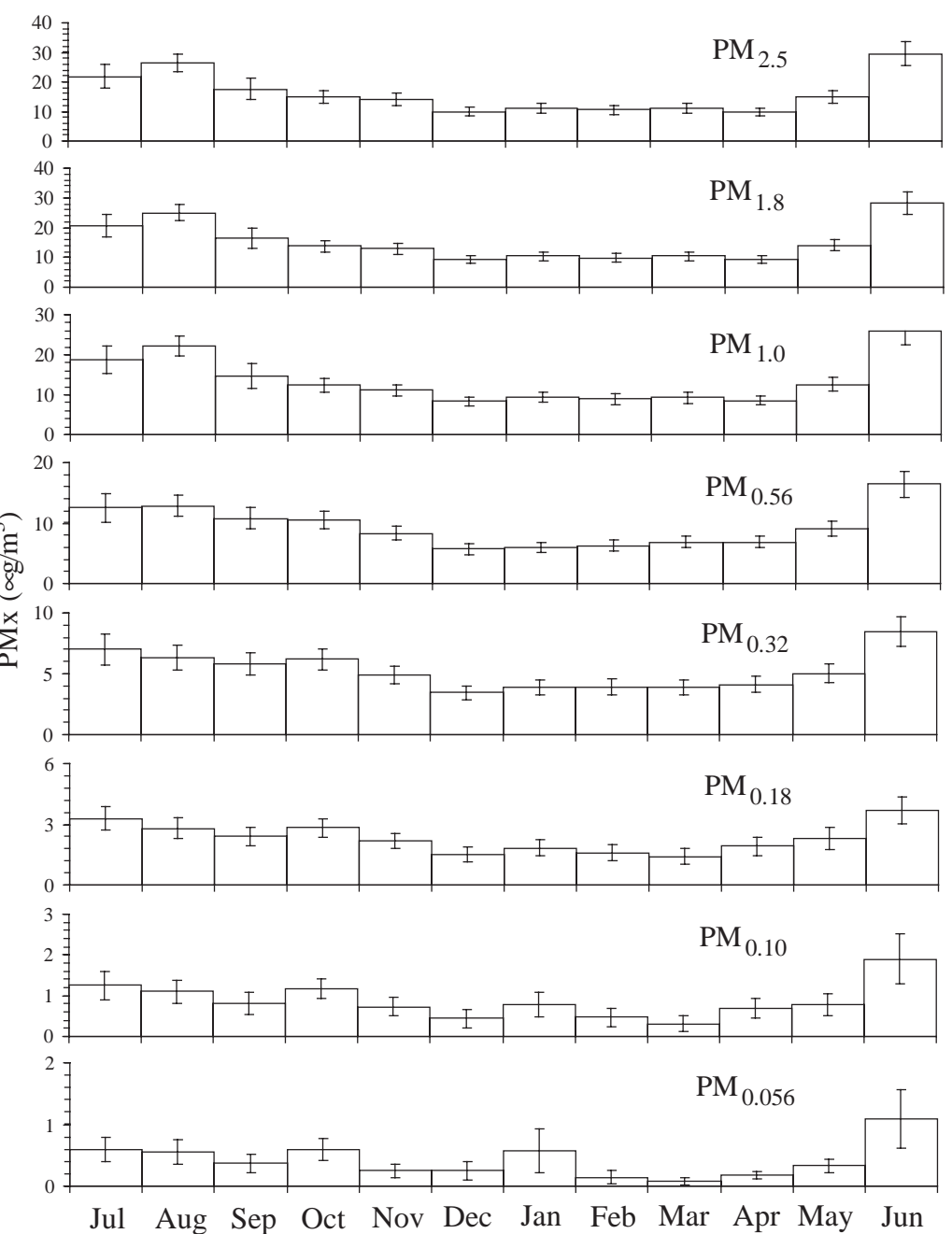

Fig. 2. Monthly averages of $\mathrm{PM}_{x}$ measured with the MOUDI during PAQS. The error bars correspond to the measurement standard errors.

below $2.5 \mu \mathrm{m}$ in Pittsburgh (Fig. 3a). Eighty-five percent of the $\mathrm{PM}_{2.5}$ mass is in aerosol particles smaller than $1.0 \mu \mathrm{m}$ in aerodynamic size (Fig. 3b). Fifty-five percent of the $\mathrm{PM}_{2.5}$ is $\mathrm{PM}_{0.56}$ (Fig. 3c). $\mathrm{PM}_{0.32}$ and $\mathrm{PM}_{0.18}$ constitute around $30 \%$ and $12 \%$ of the total fine aerosol mass, respectively (Fig. $3 \mathrm{~d}$ and e). The ultrafine mass contribution (below $100 \mathrm{~nm}$ ) to $\mathrm{PM}_{2.5}$ is, on average, around 5\% (Fig. 3f).

Ultrafine particles contribute $<5 \%$ of the total fine particle mass and the filter loads are low, making the measurement of the mass of these particles prone to errors during sampling and analysis. Even a few large particles bouncing from higher stages can have a big impact on the mass on the lower stages. Khlystov et al. (2004) showed that good agreement is achieved between the MOUDI and the DAASS system for particles bigger than $100 \mathrm{~nm}$, but not for the ultrafine particles (Fig. 4a).
Improved agreement is obtained when the ratios of ultrafines mass to $\mathrm{PM}_{2.5}$ and ultrafines volume to $V_{2.5}$ are compared (Fig. 4b). Comparing the ratios from the two systems can give an estimate of particles bouncing from higher stages of the MOUDI and that are collected by lower stages, in this case stages corresponding to the ultrafine particulate matter. If bounce-off is a significant problem, the ratio of masses $\left(\mathrm{PM}_{0.10} / \mathrm{PM}_{2.5}\right)$ would exceed the ratio of volumes $\left(V_{0.10} / V_{2.5}\right)$ and the corresponding points would lie in the upper left corner of Fig. 4b, which is not the case. The correlation coefficient between these two measurements is reasonable $\left(R^{2}=0.55\right)$ given the uncertainty of the ultrafine mass concentration (estimated to be around $30 \%$ ).

Variability in the absolute estimates could be due to the measurement of the ultrafine mass in the MOUDI or the fundamental differences in the measurement 

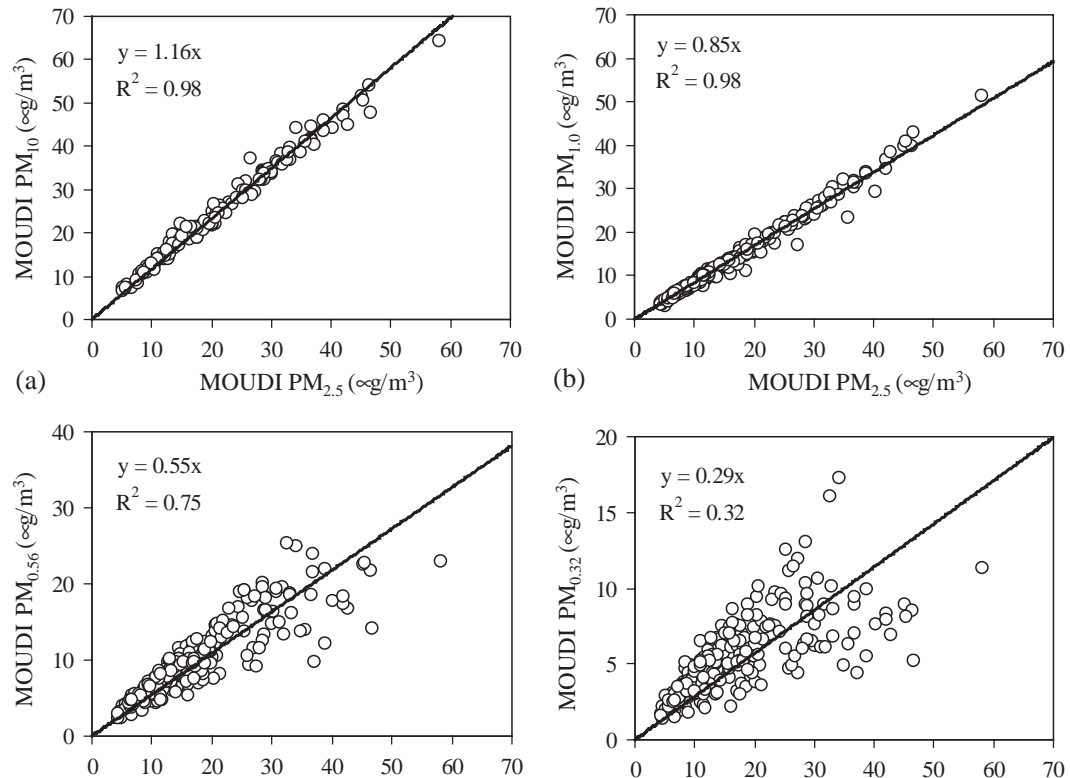

(c)
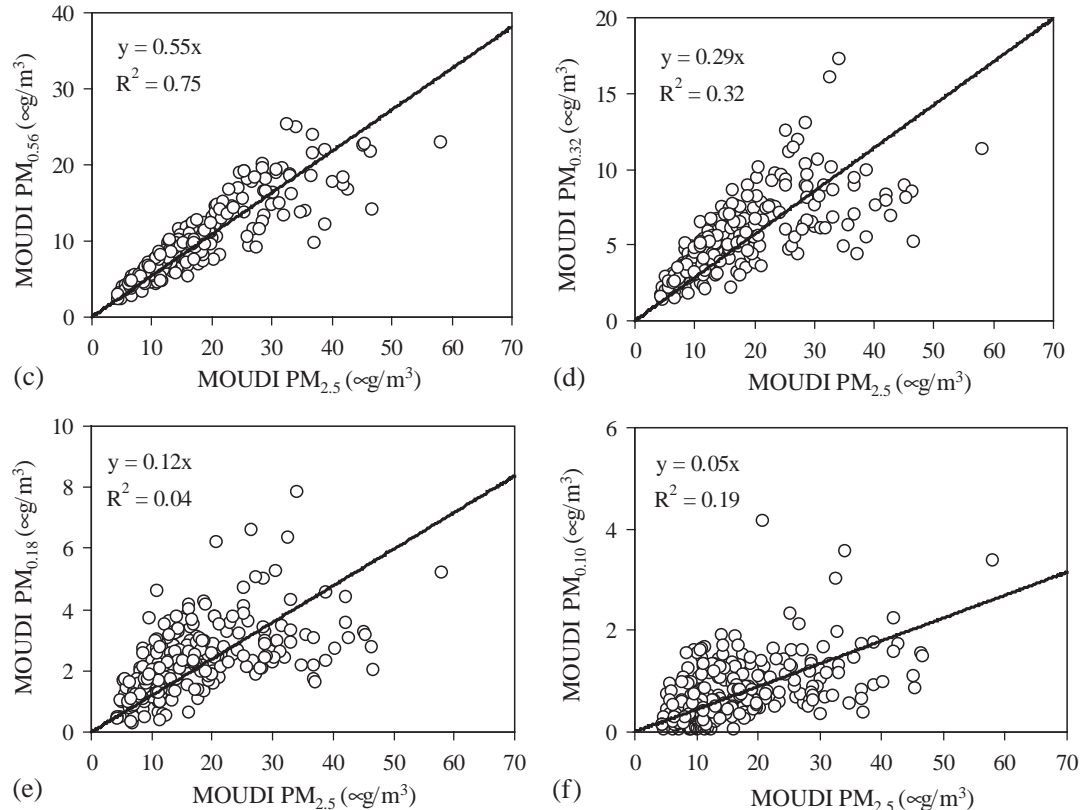

Fig. 3. Correlation of $\mathrm{PM}_{2.5}$ mass collected by the MOUDI and the integrated mass for different size bins of interest. (a) $P M_{10}$ vs. $\mathrm{PM}_{2.5}$ for 2001 , (b) $\mathrm{PM}_{1.0}$ vs. $\mathrm{PM}_{2.5}$, (c) $\mathrm{PM}_{0.56}$ vs. $\mathrm{PM}_{2.5}$, (d) $\mathrm{PM}_{0.32}$ vs. $\mathrm{PM}_{2.5}$, (e) $\mathrm{PM}_{0.18}$ vs. $\mathrm{PM}_{2.5}$, and (f) $\mathrm{PM}_{0.10}$ vs. $\mathrm{PM}_{2.5}$. Comparisons for size cuts below $\mathrm{PM}_{2.5}$ are for 2001 and 2002.
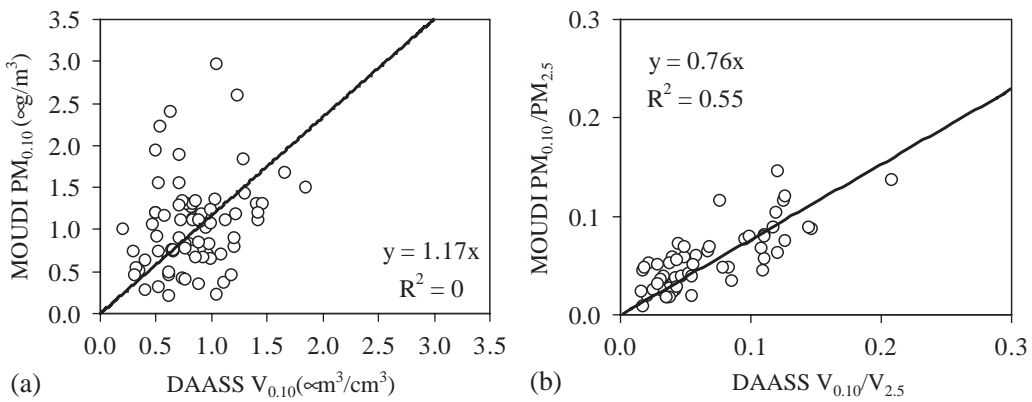

Fig. 4. Comparison of ultrafine particles between the DAASS system and the MOUDI. (a) PM $_{0.10}$ measured with the MOUDI vs. $V_{0.10}$ measured with the DAASS system. (b) Ratio of $\mathrm{PM}_{0.10}$ to $\mathrm{PM}_{2.5}$ from the MOUDI vs. ratio of $V_{0.10}$ to $V_{2.5}$ particle volume from the DAASS system.

methods employed by the MOUDI and the SMPS techniques (i.e. aerosol aerodynamic diameter vs. mobility diameter). Ambient conditions and character- istics of the aerosols (e.g. non-spherical shapes of fresh particles) could also influence these estimates (Shen et al., 2002). 


\section{Size-resolved mass distributions}

Seasonal average mass distributions collected with the MOUDI are shown in Fig. 5. Mass size distributions for each stage of the MOUDI were inverted using MICRON (Wolfenbarger and Seinfeld, 1990). For all seasons, most of the fine aerosol mass is concentrated between 0.10 and $1.0 \mu \mathrm{m}$. Summer size distributions show multiple modes. The droplet mode (around $0.7 \mu \mathrm{m})$ dominates over the size distribution. The condensation mode (around $0.2 \mu \mathrm{m}$ ) is clear only after the data is inverted to create a smooth size distribution. Fall size distributions show tri-modal distribution but in this case the condensation mode is slightly larger than the droplet mode. Winter size distributions show four modes distribution with both, the condensation and the droplet modes contributing equally to the distribution. Spring size distributions are similar to the summer, with a dominating droplet mode and lower condensation mode.

Data collected during SCAQS in southern California, using both MOUDIs and SMPS systems, showed two modes in the fine mass distributions. One mode was observed around $0.20 \mu \mathrm{m}$ (condensation mode) and the second and larger mode was at around $0.70 \mu \mathrm{m}$ (droplet mode) (John et al., 1990; Eldering et al., 1994). Size distributions measured at Fresno, CA, for two different seasons (winter and spring) with an SMPS system showed a bi-modal distribution (Lawless et al., 2001). During the winter, size distributions showed a dominant mode around $0.20 \mu \mathrm{m}$ and a smaller mode around $1.0 \mu \mathrm{m}$. The same two modes existed in the spring, but the $1.0 \mu \mathrm{m}$ mode was dominant.

\section{PM composition measurements}

Comparisons of the major components of $\mathrm{PM}_{2.5}$ in Pittsburgh between the MOUDIs and filter-based samplers are shown in Fig. 6. The organic material (OM, OC multiplied by 1.8) measurements show reasonable correlation between the samplers for both seasons $\left(R^{2}=0.55\right.$ for summer and $R^{2}=0.74$ for winter $)$. However, around $50 \%$ of the OM, is lost from the MOUDI aluminum foils during the summer (Fig. 6a). EC measurements from the MOUDI (not shown) and the filter-based sampler show agreement within experimental uncertainty. Good agreement of the organic material collected by the MOUDI and the filter-based measurements is observed during the winter intensive (Fig. 6b). EC is slightly overestimated during the winter using the MOUDI, but still within experimental error.

There are a couple of possible reasons for the loss of OC during the summer. The first is evaporation of semivolatile material, especially SOA. Volatilization of semivolatile material from impactor samplers has been reported to be as large as $50 \%$ depending on the pressure drop of the sampler, the prevalent sampling conditions, and the ratio of gas to particle concentrations in the sampled air (Zhang and McMurry, 1991). In addition, McMurry and Zhang (1989) found significant SOA volatilization from MOUDI impactors using aluminum foils as collecting media. Anderson et al. (2002) estimated that around $20 \%$ of the total $\mathrm{PM}_{2.5}$ consisted of semi-volatile organic compounds during the summer of 2000 in the Pittsburgh area. Furthermore, Cabada et al. (2003) report that between 20 and 50\% of the organic PM in the Pittsburgh area during the
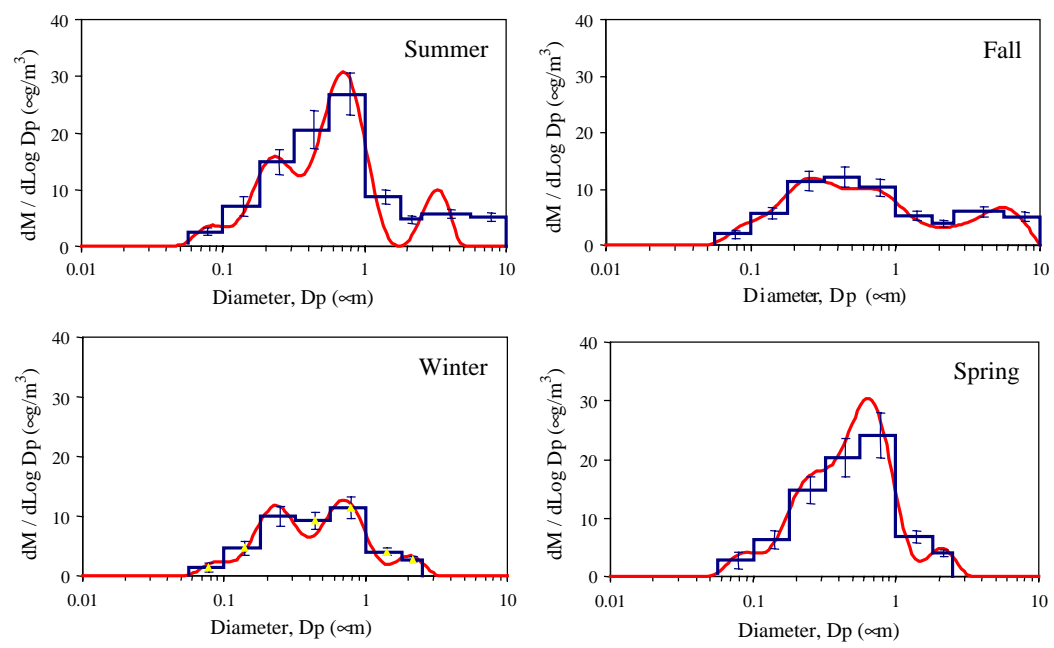

Fig. 5. Average mass size distributions from the MOUDI sampler for different seasons during PAQS. PM 10 size distributions were only collected during the summer and the fall 2001. Smoothed lines correspond to the MICRON inverted size distributions for each season. The error bars represent the sampling and analytical standard errors. 

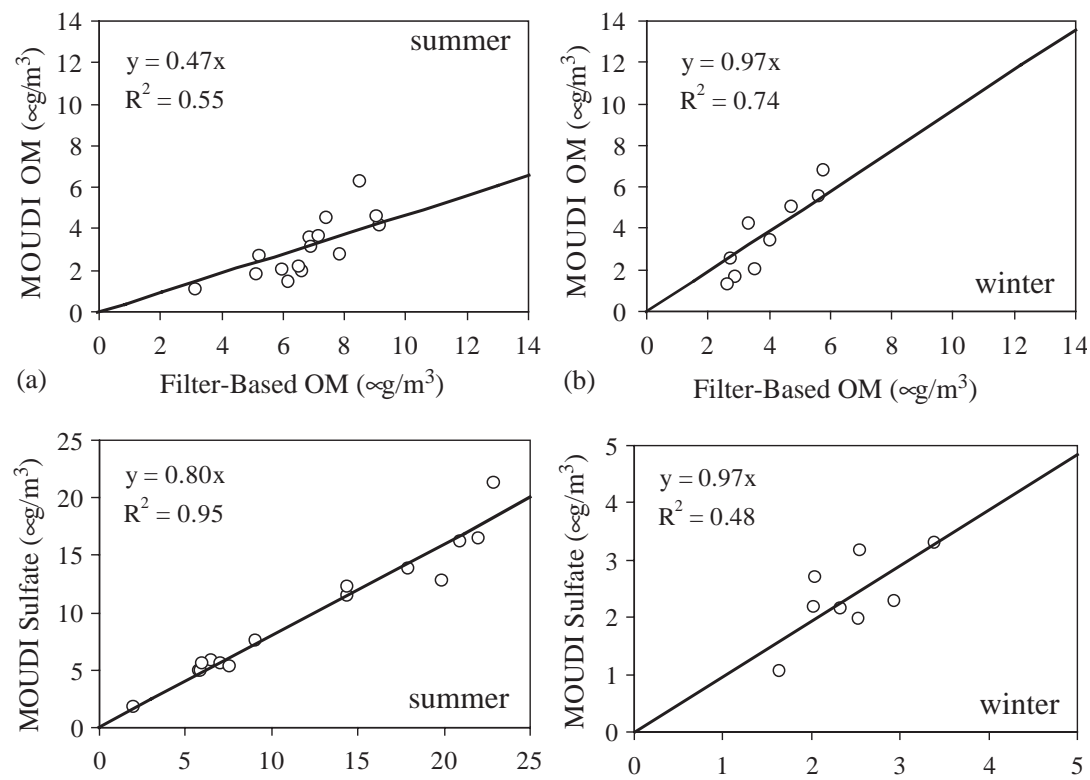

(c) Filter-Based Sulfate $\left(\mu \mathrm{g} / \mathrm{m}^{3}\right)$
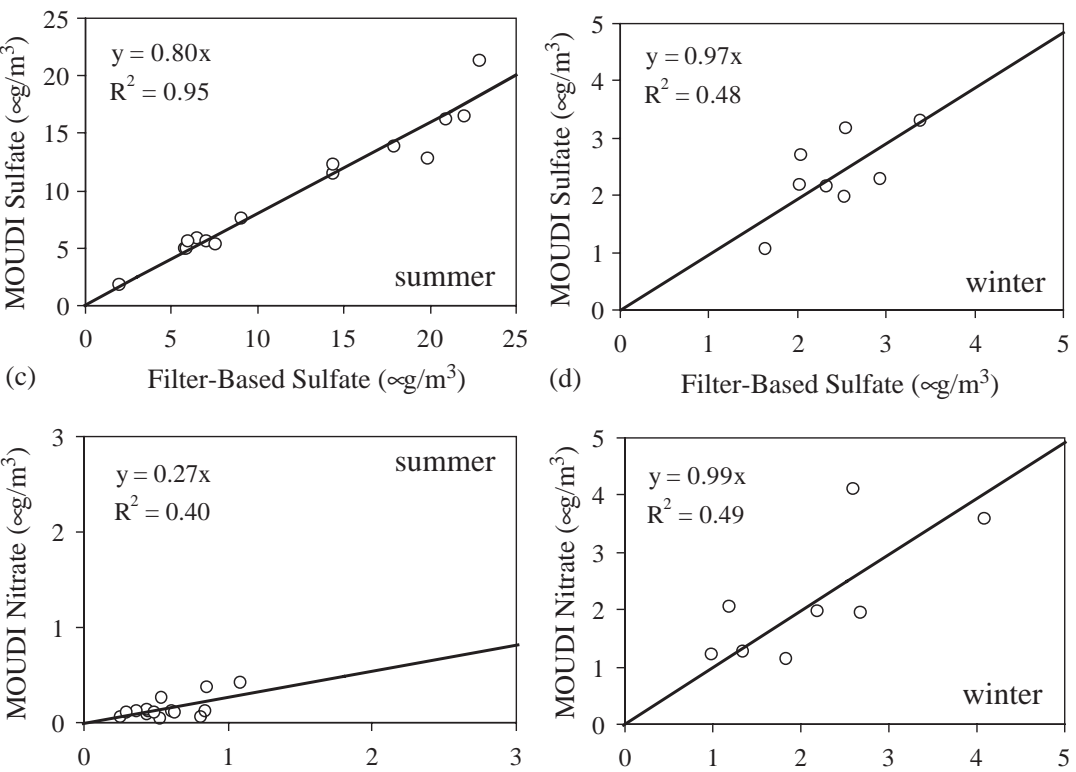

(d)

Filter-Based Sulfate $\left(\mu \mathrm{g} / \mathrm{m}^{3}\right)$

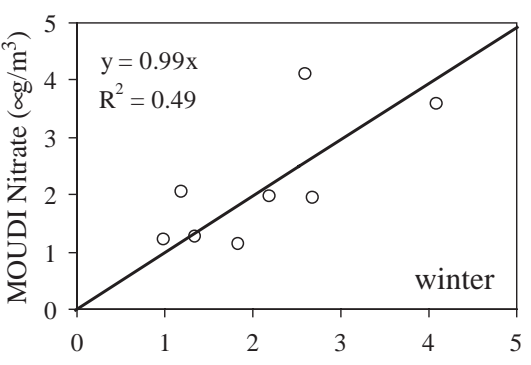

(e) Filter-Based Nitrate $\left(\mu \mathrm{g} / \mathrm{m}^{3}\right)$

(f)

Filter-Based Nitrate $\left(\mu \mathrm{g} / \mathrm{m}^{3}\right)$

Fig. 6. Comparison between measurements of individual $\mathrm{PM}_{2.5}$ compounds by the MOUDI and the integrated samplers for the two intensive periods. (a) Organic material $(\mathrm{OM}, 1.8 \times \mathrm{OC})$ measured with the MOUDI foils vs. OM measured using a denuder-based sampler during the summer intensive. (b) OM measured with the MOUDI foils vs. OM measured using an undenuded sampler during the winter intensive. The winter filter-based measurements were corrected for the positive artifact by the use of a backup quartz filter. (c) Sulfate measured with the MOUDI vs. sulfate measured with a PM speciation sampler during the summer intensive. (d) Sulfate measured with the MOUDI vs. sulfate measured on Teflon filters during the winter intensive. (e) Nitrate measured with the MOUDI vs. nitrate measured with a speciation sampler during the summer intensive. (f) Nitrate measured with the MOUDI vs. nitrate measured on Teflon filters during the summer intensive.

summer is SOA material. The contribution of SOA to the organic PM during the winter is $<10 \%$ (Cabada et al., 2002a). If all of the SOA is assumed to be semivolatile material, these estimates agree reasonably well with the mass losses from the MOUDI sampler, using aluminum foils, for both seasons.

The second explanation is related to the collection efficiency of particles on aluminum foils substrates. The use of non-greased substrates reduces the collection efficiency; especially for larger particles which are more likely to experience bounce-off. From analysis of the geometrical mean diameters (GMD) of the size distributions collected by the MOUDI using Teflon substrates, summer intensive GMDs are larger than those for the winter (summer GMD $=0.18 \mu \mathrm{m}$; winter $\mathrm{GMD}=$ $0.09 \mu \mathrm{m})$. Thus, particle loss by bounce-off may be a factor in losses of organic material from the MOUDI during the summer.

Offenberg and Baker (1999) compared PM $_{10}$ mass data from a Berner impactor using aluminum foils as substrates with data from a dichotomous sampler. The Berner impactor integrated mass accounted for only $45 \%$ of the PM mass collected by the dichotomous sampler at a Chicago urban site. They also report no significant difference between summer and winter samples, though only three data points are reported for the winter. McMurry et al. (1996) reported that MOUDIs with aluminum foil substrates in Southern 
California collected only about $50 \%$ of the organic aerosol mass compared to quartz fiber filters. In contrast, Chung et al. (2001) found good agreement for similar sampling in Central California in winter. Overall, the results of all three studies are consistent with the findings of PAQS reported here.

Fig. 6c and d show the comparison of sulfate collected by the MOUDI and the filter-based sampler for the two intensive periods. These results indicate around $20 \%$ loss of sulfate from the MOUDI during the summer. No significant difference between the MOUDI and the filterbased sampler is detected during the winter. The correlation between the samplers is high $\left(R^{2}>0.95\right)$ during the summer. Lower correlation is observed at lower sulfate levels during the winter. Comparisons in other studies between MOUDI and integrated filter samplers have shown $<10 \%$ differences between the sulfate collected by cascade impactors and sulfate collected by filter-based samplers (Sloane et al., 1991; Wall et al., 1988; Chung et al., 2001).

Fig. 6e and $\mathrm{f}$ show the comparison between the nitrate collected by the MOUDI and the filter-based sampler. Nitrate is an important constituent of $\mathrm{PM}_{2.5}$ during the winter. During the summer, however, aerosol nitrate concentrations are low due to the higher ambient temperatures and the relatively high vapor pressure of ammonium nitrate. More than $70 \%$ of the nitrate mass is lost from the MOUDI during the summer. Good agreement between the MOUDI and the filter-based sampler is observed during the winter. Several studies have reported small discrepancies in the measurement of nitrate with cascade impactors and filter-based samplers in California. Zhang and McMurry (1992) reported that a cascade impactor measures from $10 \%$ to $20 \%$ less nitrate than a denuded filter-based sampler. Wall et al. (1988) also reported an under-sampling of nitrate in a cascade impactor for a study done in Claremont, CA. Sloane et al. (1991) reported a difference of around 15\% between the mass collected by a MOUDI and a filterbased sampler, although they report that this difference is not statistically significant. California is characterized by nitrate concentrations that are one or two orders of magnitude higher than Pittsburgh. This could explain the significant losses as a fraction of the total in PAQS, during the summer, that still represent $0.5 \mu \mathrm{g} \mathrm{m}^{-3}$ of nitrate or less.

\section{Size-resolved mass composition}

\subsection{Summer}

The average size distributions of the major components of $\mathrm{PM}_{2.5}$ during the summer are shown in Fig. 7. The inorganic material, predominantly sulfate, has a practically bi-modal distribution, with a higher peak around $0.7 \mu \mathrm{m}$ (droplet mode) and a smaller peak around $0.2 \mu \mathrm{m}$ (condensation mode). The two modes are overlapping and the condensation mode appears as a "shoulder" in the raw measurements. Several authors (Hering and Friedlander, 1982; Wall et al., 1988; John et al., 1990; McMurry and Wilson, 1983) have reported the existence of these two modes in the size distribution of the inorganic aerosol from ambient samples. The sulfate condensation mode is associated with the gas phase oxidation of $\mathrm{SO}_{2}$ and the droplet mode is the product of heterogeneous reactions mainly in clouds and the accumulation of material from the lower mode. Measurements $50 \mathrm{~km}$ upwind (west of the central site) in Florence, PA, indicate that more than $90 \%$ of $\mathrm{PM}_{2.5}$ sulfate concentration measured at the PAQS site during July was the result of long-range transport into the area. Sulfate is an important constituent of $\mathrm{PM}_{2.5}$ in Pittsburgh during the summer (around $40 \%$ of total $\mathrm{PM}_{2.5}$ ). The effect of long-range transport of emissions and the high relative humidity in the northeast US during the summer are reflected by the sulfate concentration in the droplet mode. Ammonium size distributions are similar to those of sulfate, showing a smaller condensation mode, indicating formation of aerosol from the product of gas phase reactions, and a dominant droplet mode, indicating formation of aerosol by heterogeneous reactions (Wall et al., 1988; Walter et al., 1990). The GMD of the inorganic material for the summer is $0.36 \mu \mathrm{m}$.

The OM and EC have wide size distributions, with a peak between around $0.45 \mu \mathrm{m}$, for both compounds. This mode is the effect of long-range transport of carbonaceous material as particles grow. The condensation of secondary components (organic and sulfate) onto primary emitted particles is another mechanism of particle growth into the droplet mode (Vankatamaran and Friedlander, 1994; Pandis et al., 1993). Cabada et al. (2004) estimated that $20-50 \%$ of the total OC concentration is of secondary in origin for the Pittsburgh area, providing some material for the growth of the particles. Sulfate mass distributions indicate the influence of cloud processing for the Pittsburgh aerosol. Cloud processed organic aerosol or a higher fraction of water-soluble organics could also contribute to the increase the particle diameter. The GMD for OM during the summer is around $0.30 \mu \mathrm{m}$.

Fig. 8a shows the gravimetrically determined mass and the sum of the masses of each chemical compound identified. The sum of the identified compounds accounts for $70 \%$ of the MOUDI mass. This discrepancy is mainly the result of the ability of the Teflon filters used for the determination of mass, to retain more OM than the aluminum foils. Other potential explanations for the discrepancy are that the Teflon filters promote less bounce-off of carbonaceous particles and possibly absorb organic gases. Another possible reason 

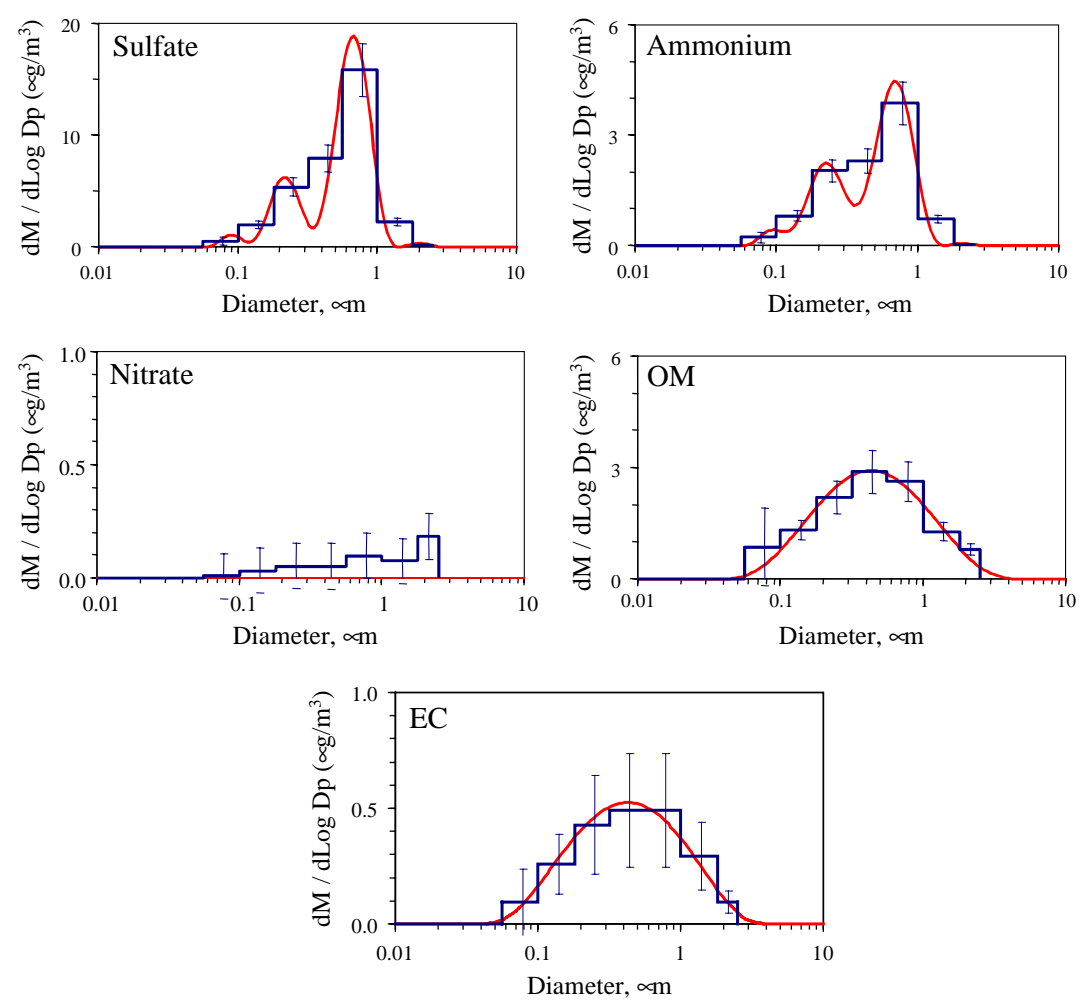

Fig. 7. Summer intensive size resolved chemical composition during PAQS, for the major components of the PM 2.5 . Also shown the MICRON-inverted size distributions (smooth lines). The error bars represent the sampling and analytical standard errors for each compound.
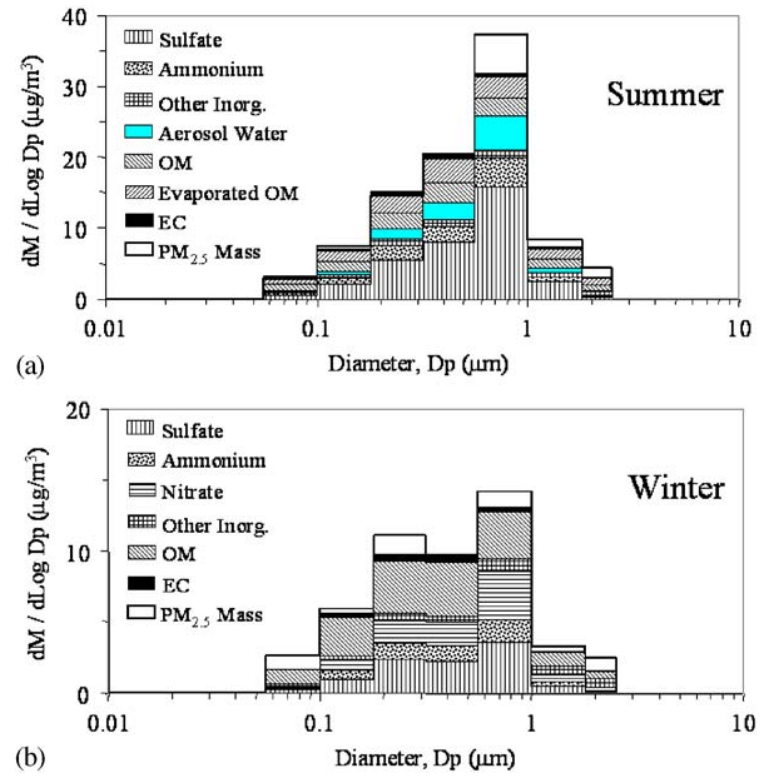

Fig. 8. Chemically resolved average distribution during the two intensive periods at PAQS (July 2001 and January 2002). The $\mathrm{PM}_{2.5}$ mass corresponds to the gravimetrically determined mass from the MOUDI stages. for the discrepancy is aerosol water. Water associated with the inorganic salts and possibly the organic material is not measured by the chemical analyses of the various compounds. Rees et al. (2004) report that Pittsburgh summer aerosol is "wet" even at low relative humidity, indicating that the mass collected by the MOUDI and measured gravimetrically contains aerosol water. Most of the "unknown" mass, namely the difference between the total gravimetric mass and the sum of the chemical species, is between 0.1 and $1.0 \mu \mathrm{m}$, where most of the mass of the inorganic salts is located. Trajectory analyses of air masses passing thru an urban area and measured at different downwind sites show that the amount of "unknown" material increases as the air mass ages in the atmosphere (Hughes et al., 1999, 2000). This is because fresh primary emissions and secondary production of aerosols modify the composition during transport. Increases in concentration of hydrophilic aerosol (via primary emissions as well as secondary production) can increase the amount of aerosol water content, leading to more "unknown" mass. For this work, if the MOUDI losses of organic material are taken into consideration (assuming they are size independent), the sum of masses of the individual compounds accounts for $85 \%$ of the gravimetrically 
determined MOUDI mass. Viidanoja et al. (2002) reported that gaseous or semi-volatile material collected on quartz filters using a cascade impactor only modify the total mass of carbon collected but had no significant impact on the shape of the original size distribution measured. Aerosol water content has been estimated to be from $10 \%$ to $15 \%$ of the $\mathrm{PM}_{2.5}$ during the summer for PAQS (Rees et al., 2004). The estimated aerosol water mass was distributed into the different MOUDI stages according to the size distribution presented by the inorganic aerosol. These two corrections are sufficient for the closure of the summer mass balance for all stages within experimental error (Fig. 8a). The closure of mass balance suggests that the shape of the OM size distribution (Fig. 7) is correct despite the significant losses during the sampling.

\subsection{Winter}

Average winter size distributions are shown in Fig. 9. Sulfate shows practically a bi-modal distribution as the summer, but in this case the droplet mode peak is not as high. Production of sulfate from gas-phase reactions (condensation mode, around $200 \mathrm{~nm}$ ) is evident during the winter, but in lower intensity than the summer. The lower mass accumulated in the droplet mode indicates that even if heterogeneous sulfate formation is the dominant pathway during the winter it is either slower or the removal of these particles occurs faster. During the winter, nitrate accounts for around $20 \%$ of the $\mathrm{PM}_{2.5}$ mass. The nitrate droplet mode suggests cloud processing and growth of the condensation mode of ammonium nitrate. Ammonium size distributions follow the same pattern as shown by sulfate and nitrate, indicating reactions of nitric acid and existing ammonia in the particulate phase and sulfur dioxide accumulate mass in the droplet mode. The GMD of the inorganic material for the winter is $0.34 \mu \mathrm{m}$ practically the same as the GMD during the summer. Unlike the summer where most of the ammonia reacts to form ammonium sulfate, a significant fraction of the ammonia in winter forms ammonium nitrate.

Carbonaceous material size distributions, $\mathrm{OM}$ and $\mathrm{EC}$, are slightly different from the summer. In winter the single mode peaks around $0.32 \mu \mathrm{m}$, indicating a greater influence of primary particles in the size distribution (Seinfeld and Pandis, 1998). The wide shape of the size distribution indicates that growth of material and longrange transport are still important factors. During the winter, the GMD for the total carbonaceous $\mathrm{PM}_{2.5}$ size
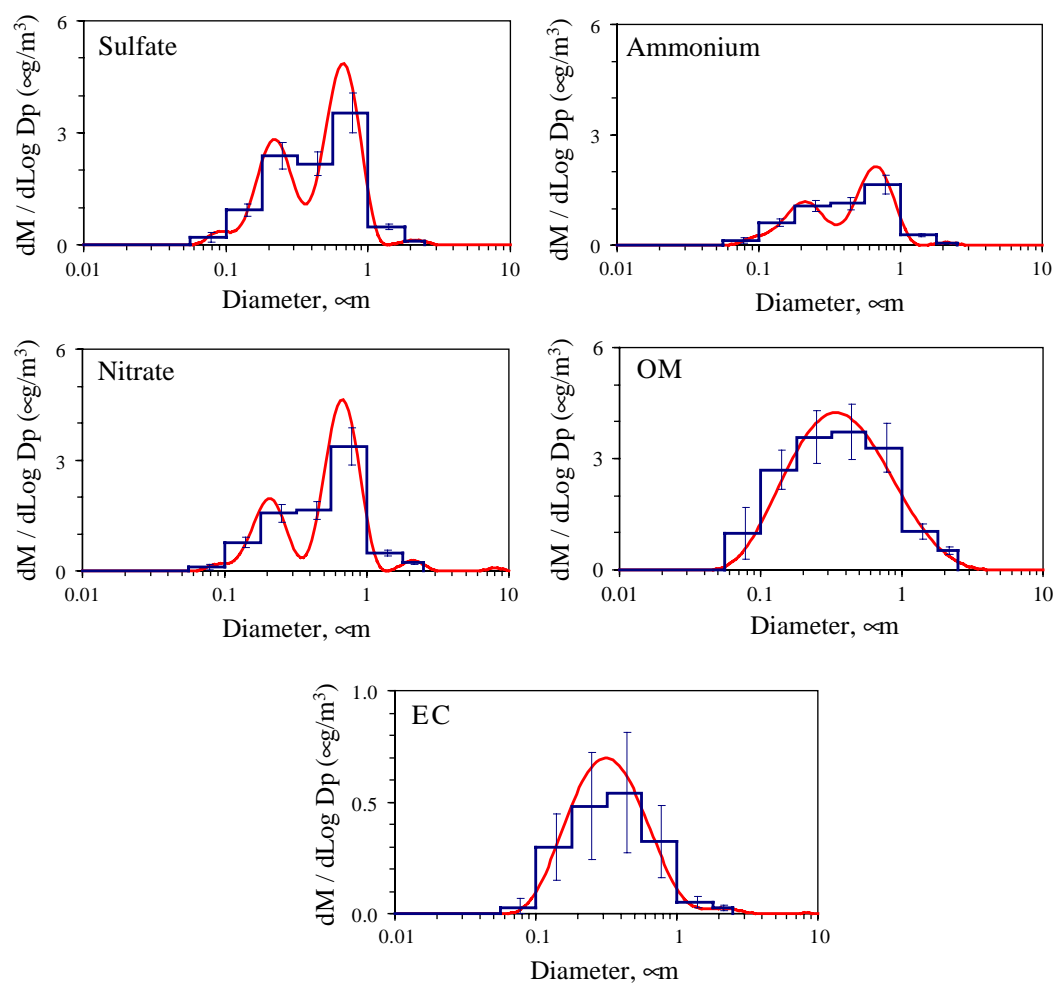

Fig. 9. Winter intensive (January 2002) size-resolved chemical composition during PAQS, for the major components of the PM 2.5 . Also shown the MICRON-inverted size distributions (smooth lines). The error bars represent the sampling and analytical standard errors for each compound. 
distributions is $0.25 \mu \mathrm{m}$, reflecting the increased winter influence of primary emissions and the slower growth to larger particle sizes.

Fig. $8 \mathrm{~b}$ shows the gravimetrically determined mass and the sum of the masses of each chemical compound identified for the winter. The sum of the identified compounds is in agreement with the measured $\mathrm{PM}_{2.5}$, within experimental errors, without any corrections.

\section{Ultrafine particles mass composition}

The chemical composition of ultrafine particles $\left(0.056<D_{\mathrm{p}}<0.10 \mu \mathrm{m}\right.$, collected by the last MOUDI stage) is shown in Fig. 10. Most of the ultrafine mass is collected by the last stage of the MOUDI. For the two intensive periods, ultrafine mass concentrations are comparable, around $0.6 \mu \mathrm{g} \mathrm{m}^{-3}$. The fraction of ultrafine mass to the total $\mathrm{PM}_{2.5}$ ranges from $0 \%$ to $11 \%$ for the summer and from $0 \%$ to $18 \%$ for the winter. Number concentrations of ultrafine particles are $23 \times 10^{3} \mathrm{~cm}^{-3}$ for the summer and $19 \times 10^{3} \mathrm{~cm}^{-3}$ for the winter (Stanier et al., 2004).

During the summer, on average $70 \%$ of the measured ultrafine mass can be explained by the sum of the concentrations from the identified components. Depending on the errors of the measurements the identified percentage ranges from $40 \%$ to $100 \%$ of the summer ultrafine mass. Carbonaceous aerosol (OM and EC) is the largest identified component of the ultrafine mass (around 50\%). Sulfate and ammonium contribute 28\%
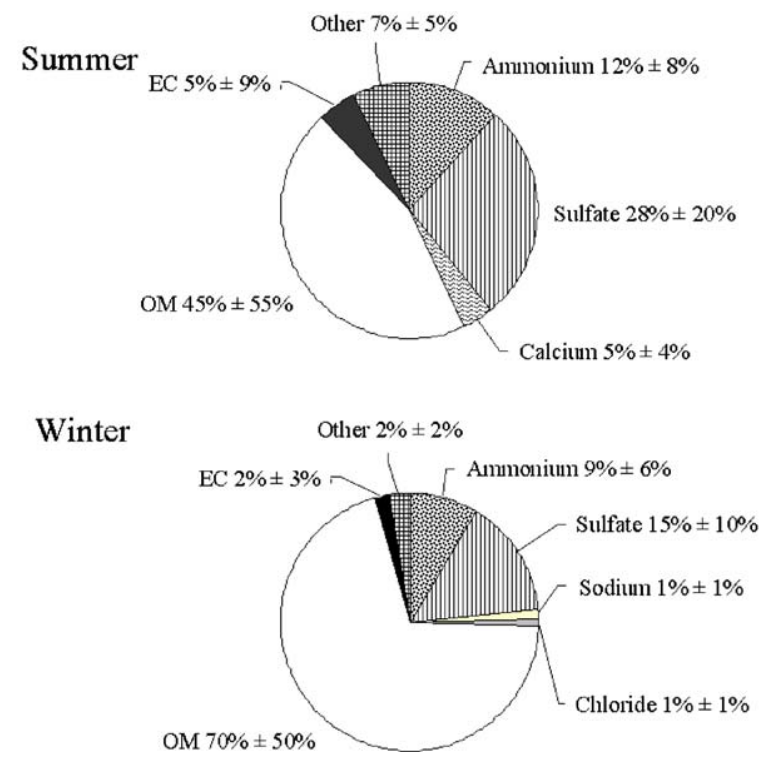

Fig. 10. Identified ultrafine mass composition $\left(56 \mathrm{~nm}<D_{\mathrm{p}}<\right.$ $100 \mathrm{~nm}$ ) for the summer and the winter intensive at PAQS. and $12 \%$, respectively. These three compounds account for around $90 \%$ of the identified ultrafine mass during the summer. The "other" fraction is inorganic material (e.g. sodium, oxalate, potassium, magnesium and chloride) with individual mass contribution $<2 \%$ of the ultrafines.

For the winter, on average $65 \%$ of the mass is accounted for. The identified chemical species explain from $40 \%$ to $100 \%$ of the ultrafine mass during the winter. The chemical composition of the ultrafine particles is different during the winter. Carbonaceous material accounts for more than $70 \%$ of the mass. Ammonium sulfate accounts for around $25 \%$ of the ultrafine mass. The high contribution of carbonaceous material during the winter is consistent with the increase in carbon emissions from combustion of material for heating purposes (Cabada et al., 2002b). A large fraction of crustal material in the ultrafine mass has been identified in studies in Central California, during the winter (Chung et al., 2001). For PAQS, the contribution of crustal compounds to the ultrafine mass is negligible, with $<1 \%$ for both summer and winter.

Southern and Central California studies indicate similar mass composition of ultrafine particles during the winter. Hughes et al. (1998) reported that most of the ultrafine particle composition in Pasadena, California, was carbonaceous material (OM and EC) during the winter $(>40 \%)$, followed by around $5-25 \%$ of trace metals. Negligible contributions of sulfate and nitrate were reported. The unidentified fraction of material in the ultrafine mass is reported to be from $23 \%$ to $43 \%$. Chung et al. (2001) reported that the ultrafine aerosol composition for Bakersfield, California, during the winter is mostly composed of inorganic material, crustal compounds, and trace metals. However, one of the major components identified is OC, contributing about $20 \%$ of the ultrafine mass. Calcium concentrations in the ultrafine mass were reported to be around $20 \%$. Considerable amounts of nitrate, sodium and sulfate were also found $(>5 \%)$. The "unknown" material in the ultrafine mass was reported to be between $0 \%$ and $50 \%$.

During September 2002, an aerosol mass spectrometer (AMS, Aerodyne Inc.) measured size distributions of sulfate, nitrate and $\mathrm{OM}$ between $30 \mathrm{~nm}$ and $2 \mu \mathrm{m}$ at PAQS main site. On average, the ultrafine mass was mostly composed of organic material (50-70\%). Sulfate was detected in the ultrafine section for particle diameters larger than $70 \mathrm{~nm}$. The sulfate contribution to the ultrafine mass varied from $20 \%$ to $50 \%$. Negligible quantities of nitrate are reported for the ultrafine mass. Results by the Aerodyne AMS are consistent with the MOUDI ultrafine mass composition for the summer. Both approaches show that $\mathrm{OM}$ is a major component of the ultrafine mass in the area followed by sulfates. 


\section{Conclusions}

Size-resolved mass distributions have been measured using a MOUDI impactor for 12 months, during the PAQS. Measurements of $\mathrm{PM}_{0.056}, \mathrm{PM}_{0.10}, \mathrm{PM}_{0.18}$, $\mathrm{PM}_{0.32}, \mathrm{PM}_{0.56}, \mathrm{PM}_{1.0}, \mathrm{PM}_{1.8}$ and $\mathrm{PM}_{2.5}$ are available for the length of the study. A seasonal dependence of all the mass fractions is observed, with higher concentrations during the summer and lower concentrations for the winter and spring. High correlation exists between $\mathrm{PM}_{2.5}$ and $\mathrm{PM}_{1.0}$.

The MOUDI $\mathrm{PM}_{10}$ concentration was around $20 \%$ less than the gravimetrically determined $\mathrm{PM}_{10}$ mass. The discrepancy is probably due to losses of coarse particles to the walls of the impactor or bounce-off from the collecting stages. Good agreement between the $\mathrm{PM}_{2.5}$ collected by the MOUDI and other integrated mass samplers is obtained for the length of the study.

Mass distributions for all seasons are dominated by the accumulation mode, with the condensation mode around $0.2 \mu \mathrm{m}$, and the droplet mode around $0.7 \mu \mathrm{m}$. Size distributions of the major inorganic compounds and carbonaceous material were measured for two intensive periods (July 2001 and January 2002). The summer is characterized by a higher peak in the droplet mode, indicating a greater influence of heterogeneous production of inorganic material (sulfate, ammonium) and significant cloud processing. OM is also abundant in the droplet mode. During the winter and fall, the condensation mode becomes more important indicating more influence from primary emissions of carbonaceous material and slower photochemical production and growth.

More than $50 \%$ of the OM is lost from the MOUDI aluminum foils as compared to a filter-based sampler during the summer. Good agreement is observed during the winter. OM losses during the summer are mainly due to volatilization of material due to higher ambient temperatures and higher concentrations of secondary organic species (i.e. SOA). Significant volatilization of nitrate from the MOUDI is also observed in the summer. Reasonable agreement between the gravimetrically determined mass and the sum of the masses of the individual compounds is achieved if the losses of $\mathrm{OM}$ and nitrate are considered and if the water content of the aerosol is taken into account.

Reasonable correlation is observed between the MOUDI and the DAASS when the ratios of $\mathrm{PM}_{0.1}$ to $\mathrm{PM}_{2.5}$ and $V_{0.1}$ to $V_{2.5}$ are compared between each other. Possible bouncing of particles in the MOUDI is introducing an error $<30 \%$ for the ultrafine mass and composition. Winter and summer intensives ultrafine concentrations are somewhat different, with higher contribution of carbonaceous material during the winter. Number concentrations are slightly higher during the winter. During the summer, carbonaceous material contributes around $50 \%$ and sulfate and ammonium contribute $28 \%$ and $12 \%$ of the ultrafine mass, respectively. Small amounts of other inorganic material (e.g. sodium, oxalate, potassium, magnesium and chloride) account for around $10 \%$ of the ultrafine mass. During the winter, carbonaceous material accounts for more than $70 \%$ of the ultrafine mass, indicating a greater influence of primary emissions from combustion sources to the Pittsburgh ultrafine aerosol. Sulfate and ammonium are the most important inorganic compounds in the ultrafine regime accounting for around $25 \%$ of the mass. Negligible amounts of crustal material are detected in the ultrafine particles in either summer or winter.

\section{Acknowledgements}

This research was conducted as part of the Pittsburgh Air Quality Study that was supported by US Environmental Protection Agency under contract R82806101 and the US Department of Energy National Energy Technology Laboratory under contract DE-FC2601NT41017. This paper has not been subject to EPA's required peer and policy review, and therefore does not necessarily reflect the views of the Agency. No official endorsement should be inferred.

\section{References}

Anderson, R.R., Martello, D.V., Rohar, P.C., Straizar, B.R., Tamilia, J.P., Waldner, K., White, C.M., Modey, W.K., Mangelson, N.F., Eatough, D.J., 2002. Sources and composition of $\mathrm{PM}_{2.5}$ at the National Energy Technology Laboratory in Pittsburgh during July and August 2000. Energy and Fuels 16, 261-269.

Cabada, J.C., Pandis, S.N., Robinson, A.L., Subramanian, R., Polidori, A., Turpin, B.J. 2002a. The contribution of secondary organic aerosol to $\mathrm{PM}_{2.5}$ concentrations in Pittsburgh. Presented at the 21st Annual AAAR Conference, Charlotte, NC.

Cabada, J.C., Pandis, S.N., Robinson, A.L., 2002b. Sources of atmospheric carbonaceous particulate matter in Pittsburgh, Pennsylvania. Journal of the Air and Waste Management Association 52, 732-741.

Cabada, J.C., Pandis, S.N., Robinson, A.L., Subramanian, R., Polidori, A., Turpin, B.J., 2004. Estimating the secondary organic aerosol contribution to $\mathrm{PM}_{2.5}$ using the $\mathrm{OC}$ to $\mathrm{EC}$ ratio method. Aerosol Science and Technology, submitted for publication.

Chung, A., Herner, J.D., Kleeman, M.J., 2001. Detection of ultrafine particles at Bakersfield, California. Environmental Science and Technology 35, 2184-2190.

Dockery, D.W., Pope, C.A., Xu, X., Splenger, J.D., Ware, J.H., Ferris, B.G., Speitzer, F.E., 1993. Mortality risks of air pollution: a prospective cohort study. New England Journal of Medicine 329, 1753-1759. 
Donalson, K., Brown, D., Clouter, A., Duffin, R., MacNee, W., Renwick, L., Tran, L., Stone, V., 2002. The pulmonary toxicology of ultrafine particles. Journal of Aerosol Medicine 15, 213-220.

Eldering, A., Cass, G.R., Moon, K.C., 1994. An air monitoring network using continuous particles size distribution monitors: connecting pollutant properties to visibility via Mie scattering calculations. Atmospheric Environment 28, 2733-2749.

Environmental Protection Agency, 1996. Air quality criteria for particulate matter. EPA/600/P-65/001.

Ferin, J., Oberdorster, G., Penney, D.P., 1992. Pulmonary retention of ultrafine and fine particles in rats. American Journal of Respiratory Cell and Molecular Biology 6, 535,542 .

Hering, S.V., Friedlander, S.K., 1982. Origins of aerosol sulfur size distributions in the Los Angeles basin. Atmospheric Environment 16, 2647-2656.

Hinds, W.C., 1998. Aerosol Technology: Properties, Behavior and Measurement of Airborne Particles, 2nd Edition. Wiley, New York.

Hughes, L.S., Cass, G.R., Gone, J., Ames, M., Olmez, I., 1998. Physical and chemical characterization of atmospheric ultrafine particles in the Los Angeles area. Environmental Science and Technology 32, 1153-1157.

Hughes, L.S., Allen, J.O., Kleeman, M.J., Johnson, R.J., Cass, G.R., Gross, D.S., Gard, E.E., Galli, M.E., Morrical, B.D., Fergenson, D.P., Diennes, T., Noble, C.A., Liu, D.Y., Silva, P., Prather, K.A., 1999. Size and composition distribution of atmospheric particles in southern California. Environmental Science and Technology 33, 3506-3515.

Hughes, L.S., Allen, J.O., Bhave, P., Kleeman, M.J., Cass, G.R., Lui, D.-Y., Fergenson, D.P., Morrical, B.D., Prather, K.A., 2000. Evolution of atmospheric particles along trajectories crossing the Los Angeles basin. Environmental Science and Technology 34, 3058-3068.

John, W., Wall, S.M., Ondo, J.L., Winklmayr, W., 1990. Modes in the size distributions of atmospheric inorganic aerosol. Atmospheric Environment 24A, 2349-2359.

Khlystov, A., Stanier, C.O., Pandis, S.N., 2004. An algorithm for combining electrical mobility and aerodynamic size distributions data when measuring ambient aerosol. Aerosol Science and Technology, submitted for publication.

Lawless, P.A., Rodes, C.E., Evans, G., Sheldon, L., Creason, J., 2001. Aerosol concentrations during the 1999 Fresno exposure studies as functions of size, season and meteorology. Aerosol Science and Technology 34, 66-74.

Marple, V.A., Rubow, K.L., Behm, S.M., 1991. A microorifice uniform deposit impactor (MOUDI): description, calibration and use. Aerosol Science and Technology 14, 434-446.

McMurry, P.H., Wilson, J.C., 1983. Droplet phase (heterogeneous) and gas phase (homogeneous) contribution to secondary ambient aerosol formation as functions of relative humidity. Journal of Geophysical Research 88, 5101-5108.

McMurry, P.H., Zhang, X.Q., 1989. Size distributions of ambient organic and elemental carbon. Aerosol Science and Technology 10, 430-437.

McMurry, P.H., Zhang, X., Chung-Te, L., 1996. Issues in aerosol measurement for optics assessments. Journal of Geophysical Research 101, 19189-19197.
Oberdorster, G., 1995. Lung particle overload, implications for occupational exposures to particles. Regulatory Toxicology and Pharmacology 21, 123-135.

Oberdorster, G., 2001. Pulmonary effects of inhaled ultrafine particles. International Archives of Occupational and Environmental Health 74, 1-8.

Oberdorster, G., Yu, C.P., 1990. The carcinogenic potential of inhaled diesel exhaust, a particle effect. Journal of Aerosol Science 21, 397-401.

Oberdorster, G., Ferin, J., Lehnert, B.E., 1994. Correlation between particle size, in-vivo particle persistence, and lung injury. Environmental Health Perspectives 102, 173-179.

Offenberg, J.H., Baker, J.E., 1999. Aerosol size distributions of polycyclic aromatic hydrocarbons in urban and over-water atmospheres. Atmospheric Environment 33, 3324-3331.

Pak, S.S., Liu, B.Y.H., Rubow, KL., 1992. Effect of coating thickness on particle bounce in intertial impactors. Aerosol Science and Technology 16, 141-150.

Pandis, S.N., Wexler, A.S., Seinfeld, J.H., 1993. Secondary organic aerosol formation and transport-II. Predicting the ambient secondary organic aerosol size distribution. Atmospheric Environment 27A, 2403-2416.

Rees, S.L., Robinson, A.L., Khylstov, A.Y., Stanier, C.O., Subramanian, R., Cabada, J.C., Wittig, B., Takahama, S., Davidson, C., Pandis, S.N., 2004. Mass Balance Closure and the Federal Reference Method for $\mathrm{PM}_{2.5}$ in Pittsburgh, PA. Atmospheric Environment, this issue, doi:10.1016/ j.atmosenv.2004.03.016.

Seinfeld, J.H., Pandis, S.N., 1998. Atmospheric Chemistry and Physics: From Air Pollution to Global Change. Wiley, New York.

Shen, S., Jaques, P.A., Zhu, Y., Geller, M.D., Sioutas, C., 2002. Evaluation of the SMPS-APS system as a continuous monitor for measuring $\mathrm{PM}_{2.5}, \mathrm{PM}_{10}$ and coarse (PM2.5-10) concentrations. Atmospheric Environment 36, 3939-3950.

Sloane, C.S., Watson, J., Chow, J., Pritchett, L., Richards, L.W., 1991. Size-segregated fine particulate measurements by chemical species and their impact on visibility impairment in Denver. Atmospheric Environment 25A, 1013-1024.

Stanier, C.O., Khlystov, A.Y., Chan, W.R., Mandiro, M., Pandis, S.N., 2004. A method for the in-situ measurement of aerosol water content of ambient aerosols: The dry-ambient aerosol size spectrometer (DAASS). Aerosol Science and Technology, submitted for publication.

Subramanian, R., Khlystov, A., Cabada, J.C., Robinson, A.L., 2004. Measurement of Positive and Negative Artifacts with Denuded and Undenuded Sampler Configurations. Aerosol Science and Technology, submitted for publication.

Turpin, B.J., Lim, H.J., 2001. Species contributions to $\mathrm{PM}_{2.5}$ mass concentrations: revisiting common assumptions for estimating organic mass. Aerosol Science and Technology $35,602-610$.

Vankatamaran, C., Friedlander, S.K., 1994. Size distributions of polycyclic aromatic hydrocarbons and elemental carbon. 2. Ambient measurements and effects of atmospheric processes. Environmental Science and Technology 28, 563-572.

Viidanoja, J., Kerminen, V.-M., Hillamo, R., 2002. Measuring the size distribution of atmospheric organic and black carbon using impactor sampling coupled with thermal carbon analysis: method development and uncertainties. Aerosol Science and Technology 36, 607-616. 
Wall, S.M., John, W., Ondo, J.L., 1988. Measurement of aerosol size distributions for nitrate and major ionic species. Atmospheric Environment 22, 1649-1656.

Wexler, A.S., Ondov, J.M., 1998. Where do particulate toxins reside? An improved paradigm for the structure and dynamics of the urban mid-Atlantic aerosol. Environmental Science and Technology 32, 2547-2555.

Whitby, K.T., 1978. The physical characteristics of sulfur aerosols. Atmospheric Environment 12, 135-159.

Wittig, B., Pandis, S.N., Hering, S., Kirby, B., Khylstov, A.Y., Takahama, S., Davidson, C., 2004a. Semi-continous PM2.5 inorganic composition measurements during the Pittsburgh Air Quality Study. Atmospheric Environment, this issue, doi:10.1016/j.atmosenv.2004.03.002.
Wittig, B., Anderson, N., Khlystov, A.Y., Pandis, S.N., Davidson, C., Robinson, A.L., 2004b. Pittsburgh Air Quality Study overview. Atmospheric Environment, this issue, doi:10.1016/j.atmosenv.2004.03.003.

Wolfenbarger, J.K., Seinfeld, J.H., 1990. Inversion of aerosol size distribution data. Journal of Aerosol Science 21, 227-247.

Zhang, X.Q., McMurry, P.H., 1991. Theoretical analysis of evaporative losses of adsorbed and absorbed species during atmospheric aerosol sampling. Environmental Science and Technology 25, 456-459.

Zhang, X.Q., McMurry, P.H., 1992. Evaporative losses of fine particulate nitrates during sampling. Atmospheric Environment 26A, 3305-3312. 